\title{
Effect of insulin on the utilization of propionate in gluconeogenesis in sheep
}

\author{
BY RONALD P. BROCKMAN \\ Department of Animal and Poultry Science, University of Saskatchewan, Saskatoon, \\ Saskatchewan $S 7 N 0 W 0$, Canada
}

(Received 5 December 1988 - Accepted 4 January 1990)

\begin{abstract}
The effects of insulin on the utilization of propionate in glucose synthesis were studied in fed and fasted sheep. Insulin was infused at $0 \cdot 40 \mu \mathrm{U} / \mathrm{h}$ into the mesenteric vein. Glucose was infused to prevent

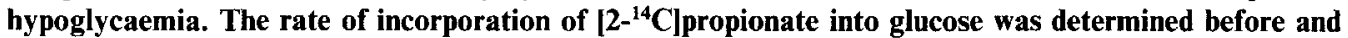
during insulin infusion. After 150 min of insulin infusion endogenous glucose synthesis was about $\mathbf{7 0} \%$ of control values, whereas the incorporation of $\left[{ }^{14} \mathrm{C}\right]$ propionate into plasma glucose was $94 \%$ of control values. In contrast, the incorporation of other glucose precursors into glucose was decreased $30-50 \%$ by insulin. Therefore, insulin does not appear to decrease the utilization of propionate in gluconeogenesis. These results are consistent with the proposition that insulin differentially affects the rate of incorporation of glucose precursors into glucose in ruminant animals.
\end{abstract}

Insulin: Propionate metabolism: Gluconeogenesis: Sheep

Ruminant animals convert dietary carbohydrate to short-chain fatty acids as a result of the fermentative nature of their digestion. Thus, little or no dietary carbohydrate is absorbed as hexose sugar (Bergman et al. 1970) and glucose needs must be met by gluconeogenesis. Gluconeogenesis is greatest in the fed state (Katz \& Bergman, 1969 b) when the absorption of precursors and insulin concentrations are greatest (Baird et al. 1980).

Previous studies (Brockman, 1985; Brockman \& Laarveld, 1986) have shown that insulin inhibits gluconeogenesis in sheep by reducing the hepatic extraction efficiency of some glucogenic compounds, such as lactate, alanine, glutamine and glycerol. Since those studies were conducted on fasted sheep, propionate was not examined. However, the rate of utilization of propionate, a major glucogenic precursor (Bergman et al. 1966; Judson \& Leng, 1973) in fed animals, may not be influenced by insulin. First, the hepatic extraction of propionate is high in fed animals (Bergman \& Wolff, 1971). Second, the infusion of propionate into cows did not affect the hepatic extraction efficiency of propionate despite its elevation of insulin concentrations (Baird et al. 1980). The purpose of the present study was to determine if insulin alters the rate of utilization of propionate in glucose synthesis.

\section{MATERIALS AND METHODS}

Mature, non-lactating, non-pregnant, mixed-breed (predominantly Columbia $\times$ Suffolk) ewes weighing 51 (SE 1$) \mathrm{kg}(n 6)$ were used in these experiments. The sheep were maintained in a temperature-controlled $\left(20^{\circ}\right)$ room with constant lighting. They received a maintenance diet of 900 g lucerne (Medicago sativa) pellets daily. In the fed experiments feed was divided into twenty-four equal hourly portions. For the starved experiments the sheep were given $450 \mathrm{~g}$ twice daily and were last fed $36 \mathrm{~h}$ before experimentation. Water and salt blocks were provided ad lib. Treatment of the animals conformed with the principles outlined in the Guide to the Care and Use of Experimental Animals (Canadian Council on Animal Care, 1984). 


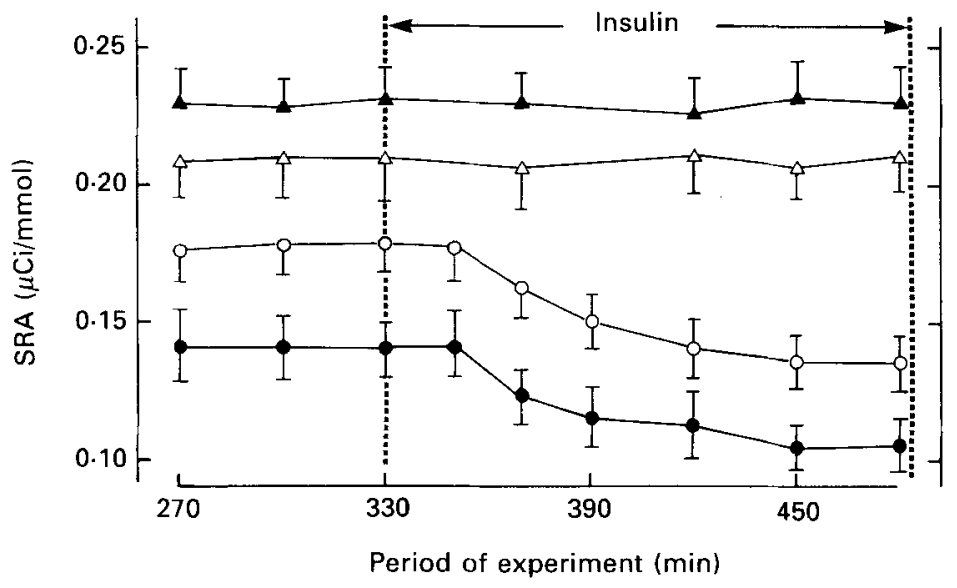

Fig. $1 .{ }^{14} \mathrm{C}$ specific radioactivities (SRA) of glucose $(\boldsymbol{O}, O)$ and propionate $(\boldsymbol{\Lambda}, \triangle)$ in the plasma of fed $(\boldsymbol{\Lambda}, \boldsymbol{O})$ and fasted $(\triangle, O)$ sheep before and during insulin infusion. Values are the means with their standard errors, represented by vertical bars, for five sheep.

At least 1 week before experimentation, polyvinyl catheters $(2.50 \times 1.50 \mathrm{~mm})$ were surgically placed in the femoral artery and portal and femoral veins and a mesenteric vein tributary (Katz \& Bergman, $1969 a)$. A polyvinyl catheter $(1.50 \times 1.00 \mathrm{~mm})$ was placed into a jugular vein the evening before experimentation. The patency of the catheters was maintained by filling them with heparinized saline $(9 \mathrm{~g}$ sodium chloride $/ 1 ; 500 \mathrm{U} / \mathrm{ml})$. During the experiments the catheters were flushed every $15 \mathrm{~min}$ with saline.

The 'fed' experiments were initiated (at zero time) by giving a priming dose of $4.0 \mu \mathrm{Ci}$ [2-14C]propionate (New England Nuclear, Boston, MA, USA) followed by continuous infusion at $4.5 \mu \mathrm{Ci} / \mathrm{h}$ via the mesenteric catheter. In the 'fasted' experiments the priming dose consisted of $4 \mu \mathrm{Ci}$ radioactive isotope and $17 \mathrm{mmol}$ unlabelled propionate followed by continuous infusion at $5.2 \mu \mathrm{Ci} / \mathrm{h}$ and $22 \mathrm{mmol} / \mathrm{h}$ respectively. In the latter, unlabelled propionate was infused intramesenterically to approximate the entry rate of propionate to fed animals. After 150 min of infusion, $\left[6-{ }^{3} \mathrm{H}\right]$ glucose (New England Nuclear) was infused at $20 \mu \mathrm{Ci} / \mathrm{h}$ via the femoral venous catheter following a priming dose of $30 \mu \mathrm{Ci}$. At $330 \mathrm{~min}$ (after 330 and $150 \mathrm{~min}$ of infusion of labelled propionate and glucose respectively) the insulin (crystalline bovine insulin, Lilly Research Laboratories, Indianapolis, IN, USA) infusion via the mesenteric venous catheter was initiated and continued for $150 \mathrm{~min}$ at $0.4 \mathrm{mU} / \mathrm{kg}$ per min. Insulin-free carrier was infused during the $0-330 \mathrm{~min}$ interval. Glucose (Dextrose, Rogar/STB, London, Ontario) was infused via the jugular venous catheter at rates to maintain euglycaemia (Brockman, 1985).

Blood samples were taken from the portal venous and arterial catheters at $-20 \mathrm{~min}$ (for background radioactivity), 210,240,270, 300 and $330 \mathrm{~min}$, and at $350,370,390,420,450$ and $480 \mathrm{~min}$ after initiation of $\left[2-{ }^{14} \mathrm{C}\right]$ propionate infusion. The blood samples were taken in heparinized syringes and transferred into tubes chilled on ice. The blood was centrifuged and the plasma was stored at $-20^{\circ}$ in vials containing $3.0 \mathrm{mg}$ EDTA $/ \mathrm{ml}$ plasma. Portions of plasma for glucagon analysis also contained 250 kallikrein inactivator units of aprotinin (Trasylol, Boehringer-Ingleheim, Dorval, Quebec) per ml.

All infusion solutions were made up in pyrogen-free sterile saline. The insulin solution also contained ovine plasma $(50 \mathrm{ml} / \mathrm{l})$ and ovine albumin $(2 \mathrm{~g} / 1)$. All solutions were infused by a peristaltic pump at a delivery rate of $0.30 \mathrm{ml} / \mathrm{min}$. 
Propionate concentrations and radioactivities were determined in portal plasma with a Pye 104 gas-liquid chromatograph (Brockman \& Greer, 1980). Glucose concentrations were determined in arterial plasma with a commercial kit (Statzyme, Worthington, Diagnostics, Freehold, NJ, USA). Arterial plasma glucose radioactivity was determined by isolation as potassium gluconate (Blair \& Segal, 1960). Insulin and glucagon concentrations in portal plasma were determined by radioimmunoassay using a buffer system previously described (Brockman, 1979). Glucagon antiserum was GP26 (Brockman \& Manns, 1985). Radio-iodinated insulin and glucagon were purchased from New England Nuclear.

The rate of appearance of glucose $\left(\mathrm{RA}_{\mathrm{G}}\right)$ was calculated using the equation for nonsteady state conditions (DeBodo et al. 1964) as validated for sheep (Brockman, 1984). Endogenous $\mathrm{RA}_{\mathrm{G}}$ equals $\mathrm{RA}_{\mathrm{G}}$ minus the rate of infusion of glucose. Propionate entry rate $\left(\mathrm{RA}_{\mathrm{p}}\right)$ was determined from the infusion rate of $\left[2-{ }^{14} \mathrm{C}\right]$ propionate $(\mu \mathrm{Ci} / \mathrm{min}):$ specific radioactivity of propionate $\left(\mathrm{SRA}_{\mathrm{p}}, \mu \mathrm{Ci} / \mathrm{mmol}\right.$ ) ratio in portal plasma. Portal plasma was used rather than arterial plasma because the larger amount of propionate in the former allows for more accurate determination of SRA . Since the source of plasma propionate is absorption from the gut, labelled and unlabelled propionate enter the plasma through the portal vein. Therefore, unless the liver removes labelled and unlabelled propionate at different rates, the $\mathrm{SRA}_{\mathrm{p}}$ should be the same in portal venous and arterial plasma.

The proportion of propionate used in glucose synthesis was calculated as

$$
\left(\left(\left(\mathrm{SRA}_{\mathrm{G}} / 2\right) / \mathrm{SRA}_{\mathrm{p}}\right) \times \mathrm{RA}_{\mathrm{G}} \times 2\right) \times\left(\mathrm{SRA}_{\mathrm{p}} /\left(\left[{ }^{14} \mathrm{C}\right] \text { propionate infusion rate }\right)\right),
$$

which reduces to

$$
\left(\mathrm{SRA}_{G}\right) \times\left(\mathrm{RA}_{\mathrm{G}}\right) /\left(\left[{ }^{14} \mathrm{C}\right] \text { propionate infusion rate }\right),
$$

where $\mathrm{SRA}_{\mathrm{G}}$ represents the specific radioactivity of glucose $(\mu \mathrm{Ci} / \mathrm{mmol})$.

The glucose synthesized from propionate was calculated as:

$$
\left(\mathrm{SRA}_{\mathrm{G}} /\left(\mathrm{SRA}_{\mathrm{p}} \times 2\right)\right) \times \mathrm{RA} \text {. }
$$

The factor 2 in the equation corrects for differences in the number of carbon atoms per molecule. These equations assume steady-state conditions existed. The calculations were based on $\mathrm{SRA}_{\mathrm{C}}$ values measured during the last $0.5 \mathrm{~h}$ before insulin infusion was begun and the last $0.5 \mathrm{~h}$ of insulin infusion. Glucose concentrations, endogenous $\mathrm{RA}_{\mathrm{G}}$ and ${ }^{14} \mathrm{C} \mathrm{SRA}$, were constant during these intervals (Fig. 1), indicating that steady-state conditions existed.

In calculating the appearance of ${ }^{14} \mathrm{C}$ from propionate into glucose, the mean value for ${ }^{14} \mathrm{C}$ SRA of propionate during the last $210 \mathrm{~min}$ of $\left[{ }^{14} \mathrm{C}\right]$ propionate infusion was used since there was no change in SRA throughout both sets of experiments (Fig. 1).

Statistical significance was determined using paired $t$ tests $(\mathrm{Li}, 1964)$.

\section{RESULTS}

Concentrations of insulin, glucagon, propionate and glucose in plasma are shown in Table 1. The concentrations of propionate in the control period were similar in fed and fasted sheep indicating that the infusion rate of exogenous propionate approximated physiological entry rates. Insulin concentrations, however, were higher in the propionate-infused group. Insulin concentrations increased about $30 \mu \mathrm{U} / \mathrm{ml}$ during insulin infusion in both fed and fasted animals. The glucose infusion prevented a fall in glycaemia during the insulin infusion. Propionate and glucagon concentrations did not change significantly in both groups.

The effects of insulin on glucose and propionate metabolism are presented in Table 2. The rate of appearance of glucose and the proportion of propionate converted to glucose 
Table 1. Concentrations of insulin, glucagon, glucose and propionate, and specific radioactivities of glucose and propionate in plasma before and during insulin infusion in sheep

(Values are means with their standard errors for five sheep)

\begin{tabular}{|c|c|c|c|c|c|c|c|c|}
\hline \multirow{3}{*}{$\begin{array}{l}\text { Hormone or } \\
\text { metabolite }\end{array}$} & \multicolumn{4}{|c|}{ Fed } & \multicolumn{4}{|c|}{ Fasted + propionate } \\
\hline & \multicolumn{2}{|c|}{ Control } & \multicolumn{2}{|c|}{ Insulin } & \multicolumn{2}{|c|}{ Control } & \multicolumn{2}{|c|}{ Insulin } \\
\hline & Mean & SE & Mean & $\mathrm{SE}$ & Mean & $\mathrm{SE}$ & Mean & $\mathrm{SE}$ \\
\hline Insulin $(\mu \mathrm{U} / \mathrm{ml})$ & 12 & 2 & $39 *$ & 2 & 29 & 4 & $66^{*}$ & 8 \\
\hline Glucagon $(\mathrm{pg} / \mathrm{ml})$ & 76 & 10 & 71 & 9 & 97 & 13 & 104 & 14 \\
\hline Glucose (mM) & $3 \cdot 2$ & $0 \cdot 1$ & $3 \cdot 3$ & $0 \cdot 1$ & $3 \cdot 4$ & $0 \cdot 2$ & $3 \cdot 6$ & $0 \cdot 3$ \\
\hline Propionate (mM) & $0 \cdot 30$ & 0.01 & $0 \cdot 31$ & 0.01 & 0.35 & $0 \cdot 01$ & $0 \cdot 36$ & 0.01 \\
\hline
\end{tabular}

* Mean values were significantly different from the corresponding control values (paired $t$ test): $P<0.05$.

Table 2. Glucose rate of appearance $\left(R A_{G}\right)$, propionate conversion to glucose and propionate rate of appearance $\left(R A_{p}\right)$ before and during insulin infusion in sheep

(Values are means with the standard errors of the differences between the respective control and insulin means for five sheep)

\begin{tabular}{|c|c|c|c|c|c|c|}
\hline \multirow[b]{3}{*}{ Metabolite } & \multicolumn{3}{|c|}{ Fed } & \multicolumn{3}{|c|}{ Fasted + propionate } \\
\hline & \multirow{2}{*}{$\begin{array}{l}\text { Control } \\
\text { Mean }\end{array}$} & \multicolumn{2}{|c|}{ Insulin } & \multirow{2}{*}{$\begin{array}{l}\text { Control } \\
\text { Mean }\end{array}$} & \multicolumn{2}{|c|}{ Insulin } \\
\hline & & Mean & SED & & Mean & SED \\
\hline $\mathrm{RA}_{\mathrm{G}}(\mu \mathrm{mol} / \mathrm{min})$ & 418 & $510^{*}$ & 19 & 410 & $490^{*}$ & 17 \\
\hline Endogenous $\mathrm{RA}_{C}^{\dagger} \uparrow(\mu \mathrm{mol} / \mathrm{min})$ & 418 & $311^{*}$ & 22 & 410 & $273^{*}$ & 29 \\
\hline \multicolumn{7}{|l|}{ Glucose from propionate } \\
\hline$\mu \mathrm{mol}$ glucose $/ \mathrm{min}$ & 132 & 117 & 5 & 171 & 162 & 4 \\
\hline$\%$ endogenous $\mathbf{R A}_{\mathrm{G}}$ & 31 & $37^{*}$ & 2 & 42 & $59^{*}$ & 3 \\
\hline$\% \mathbf{R A}_{\mathrm{G}}$ & 31 & $23^{*}$ & 2 & 42 & $34^{*}$ & 2 \\
\hline $\mathrm{RA}_{\mathrm{y}}(\mu \mathrm{mol} / \mathrm{min})$ & 326 & 330 & 11 & 413 & 420 & 13 \\
\hline
\end{tabular}

* Mean values were significantly different from corresponding control values (paired $t$ test): $P<0.05$.

$\uparrow$ Calculated as $\mathrm{RA}_{\mathrm{G}}$ minus glucose infused.

were similar between fed and fasted + propionate groups during the control periods. Insulin + glucose infusion decreased endogenous $\mathrm{RA}_{\mathrm{G}}$ in both fed and fasted groups. This was associated with only a marginal $(5-10 \%)$ and non-significant reduction in the proportion of propionate converted into plasma glucose. In both groups a greater percentage of endogenous glucose was derived from propionate during insulin infusion. In contrast the utilization of other precursors in glucogenesis decreased 30 and $50 \%$ in fed and fasted sheep respectively. In fed sheep the other precursors accounted for 286 and $194 \mu \mathrm{mol}$ glucose/min and in fasted sheep 239 and $111 \mu \mathrm{mol} / \mathrm{min}$ during the control and insulin infusion periods respectively (Table 2).

\section{DISCUSSION}

Ruminant animals absorb very little propionate after $36 \mathrm{~h}$ of fasting (Lomax \& Baird, 1983). Therefore, exogenous propionate was administered to fasted sheep to provide propionate. However, administration of propionate probably changed the endocrine status away from a fasting condition. Insulin concentrations were elevated by propionate infusion 
(Brockman, 1982) such that they were higher than in fed sheep (Table 1), but glucose concentrations and hepatic glucose output were not different from those of fed animals (Table 2). The proportion of propionate converted to glucose was higher in the fasted group, probably reflecting that propionate is readily available from the infusion and elevated insulin suppresses the conversion of other glucose precursors to glucose (Brockman, 1985; Brockman \& Laarveld, 1986).

The present study showed that the rate of incorporation of propionate into glucose is not decreased by changes in insulin concentrations in plasma. This conclusion is supported by observations in cattle where the propionate extraction efficiency did not change during propionate infusion despite increases in insulin concentrations (Baird et al. 1980). The linear relationship between propionate concentrations in plasma and its utilization in glucose synthesis (Bergman et al. 1966; Judson \& Leng, 1973) is consistent with this conclusion. Certainly gluconeogenesis from propionate is less responsive than gluconeogenesis from lactate to changes in insulin concentrations (Table 1; Brockman, 1985; Brockman \& Laarveld, 1986). This differential response to insulin among glucose precursors allows for the sparing of lactate and other glucogenic metabolites when propionate availability is high. Propionate is thereby preferentially used for gluconeogenesis while lactate and glucogenic amino acids would be more readily available for other synthetic processes. Thus, the proportion of glucose derived from propionate increases.

A basis for this differential hormonal response between propionate and lactate undoubtedly is related to the fact that pyruvate carboxylase (PC;EC 6.4.1.1), but not phosphoenolpyruvate carboxykinase (GTP) (PEPCK; EC 4.1.1.32), is responsive to changes in physiological status or hormonal concentrations in ruminants (Brockman \& Manns, 1974; Filsell et al. 1969). The PC-catalysed reaction is not involved in the conversion of propionate to triose phosphate, whereas the conversion of lactate to triose phosphate utilizes both the PEPCK- and PC-catalysed reactions. Therefore, hormonalinduced changes in PC activity would alter the rate of utilization of lactate and other glucose precursors in carbohydrate synthesis without altering the rate at which propionate is used for this process.

The present study has a number of limitations. In the gluconeogenic pathway, propionate is converted to oxaloacetate (OAA). In the direct conversion of propionate to glucose the label from $\left[2-{ }^{14} \mathrm{C}\right]$ propionate is not lost (White et al. 1978). However, the labelled OAA may enter the tricarboxylic acid (TCA) cycle where the label may be lost in the cycling (White et al. 1978). If the unlabelled OAA re-enters the gluconeogenic pathway the conversion of propionate to glucose is undetected, thereby causing an underestimation of the rate of gluconeogenesis. This underestimation may be minimal (Leng \& Annison, 1963). It would be particularly small in the fasted sheep, since $80 \%$ of the label appeared in plasma glucose (Table 2).

However, underestimation of the rate of gluconeogenesis would not alter the conclusions if the loss of label by entry of OAA into TCA was not changed by the insulin-glucose infusion. If such infusion changes the entry of OAA into the TCA cycle, it probably would increase it. This contention is supported by the ability of insulin to increase the production of ${ }^{14} \mathrm{CO}_{2}$ from $\left[2,3-{ }^{14} \mathrm{C}\right]$ succinate in isolated rat hepatocytes (Bessman et al. 1986). Moreover, insulin-glucose infusions seem to be thermogenic (Ravussin \& Bogardus, 1982); presumably this increases TCA cycle activity. This would cause a reduction in the incorporation of label into glucose and would tend to exacerbate any inhibitory effect of insulin on gluconeogenesis.

Gluconeogenesis was calculated as the glucose released into the plasma. Any newly synthesized hexose phosphate that was converted to hepatic glycogen and not released in the blood as glucose would not be included in the calculations of gluconeogenesis. It is 
possible that insulin increased the rate of hepatic glycogen synthesis (Bishop et al. 1965). Thus, the rate of appearance of ${ }^{14} \mathrm{C}$ into blood glucose probably underestimated the utilization of propionate for carbohydrate synthesis during insulin infusion and overestimated any inhibitory effect of insulin on incorporation of propionate into hexose sugars. However, the effects of increased glycogen synthesis, rather than masking any inhibitory effect of insulin on gluconeogenesis, would exacerbate it. This would be of major concern only if insulin decreased hepatic output of $\left[{ }^{14} \mathrm{C}\right]$ glucose significantly. In the present study the appearance of ${ }^{14} \mathrm{C}$ into plasma glucose decreased only $5-10 \%$.

Finally, significant error could result from the rate of change in $\mathrm{SRA}_{G}$ (Brockman \& Laarveld, 1986). The glucose pool has a relatively slow turnover time of $1 \mathrm{~h}$ (Leng, 1970). A decrease in the rate of incorporation of propionate into glucose would take some time to be reflected accurately in the SRA G $_{\mathrm{G}}$. Measurements taken before equilibration cause overestimates of the rate of gluconeogenesis. However, this error was minimized by using $\mathrm{SRA}_{\mathrm{G}}$ values from the last two samples during insulin infusion. The SRA of $\left[{ }^{14} \mathrm{C}\right]$ glucose was relatively constant at that time. In conclusion, the methodological errors do not alter the validity of the findings of the present study.

It is possible that insulin increases the absolute amount of propionate converted to hexose sugar. Studies with rat liver cells suggest that insulin enhances glucose production from propionate (Soling \& Seuffert, 1975). It is not clear from the study of Soling \& Seuffert (1975) whether the estimates of glucose production included newly synthesized glycogen. If it did, release of glucose from hepatic cells may have been decreased while the total production of carbohydrate (glucose + glycogen) increased. If hexose phosphate is converted to glycogen at an increased rate and the rate at which propionate is converted to triose phosphate is not impaired, the flux of propionate to glycogen + glucose may increase. In the present study hepatic glycogen synthesis was not determined. Thus, the possibility of increased utilization of propionate in gluconeogenesis cannot be ruled out.

\section{REFERENCES}

Baird, G. D., Lomax, M. A., Symonds, H. W. \& Shaw, S. R. (1980). Net hepatic and splanchnic metabolism of lactate, pyruvate and propionate in dairy cows in vitro in relation to lactation and nutrient supply. Biochemical Journal 186, 47-58.

Bergman, E. N. (1973). Glucose metabolism in ruminants as related to hypoglycemia and ketosis. Cornell Veterinarian 63, 341-382.

Bergman, E. N., Katz, M. L. \& Kaufman, C. F. (1970). Quantitative aspects of hepatic and portal glucose metabolism and turnover in sheep. American Journal of Physiology 219, 785-793.

Bergman, E. N., Roe, W. E. \& Kon, K. (1966). Quantitative aspects of propionate metabolism and gluconeogenesis in sheep. American Journal of Physiology 211, 793-799.

Bergman, E. N. \& Wolff, J. E. (1971). Metabolism of volatile fatty acids by liver and portal-drained viscera in sheep. American Journal of Physiology 221, 586-592.

Bessman, S. P., Mohan, C. \& Zaidise, I. (1986). Intracellular site of insulin action: mitochondrial Krebs cycle. Proceedings of the National Academy of Sciences, USA 83, 5067-5070.

Bishop, J. S., Steele, R., Altszuler, N., Dunn, A., Bjerknes, C. \& DeBodo, R. C. (1965). Effects of insulin on liver glycogen synthesis and break-down in the dog. American Journal of Physiology 208, 307-316.

Blair, A. \& Segal, S. (1960). The isolation of blood glucose as potassium gluconate. Journal of Laboratory and Clinical Medicine 55, 959-964.

Brockman, R. P. (1979). Glucagon responses to exercise in sheep. Australian Journal of Biological Sciences 32, $215-220$

Brockman, R. P. (1982). Insulin and glucagon responses in plasma to intraportal infusions of propionate and butyrate in sheep (Ovis aries). Comparative Biochemistry and Physiology 73A, 237-238.

Brockman, R. P. (1984). Validation of an equation for calculation of glucose appearance during nonsteady state in sheep. Canadian Journal of Physiology and Pharmacology 62, 341-344.

Brockman, R. P. (1985). Role of insulin in regulating hepatic gluconeogenesis in sheep. Canadian Journal of Physiology and Pharmacology 63, 1460-1464.

Brockman, R. P. \& Greer, C. (1980). Effects of somatostatin and glucagon on the utilization of $\left[2-{ }^{14}\right.$ C $]$ propionate in glucose production in sheep. Australian Journal of Biological Sciences 33, 457-464. 
Brockman, R. P. \& Laarveld, B. (1986). Effect of insulin on gluconeogenesis and the metabolism of lactate in sheep. Canadian Journal of Physiology and Pharmacology 64, 1055-1059.

Brockman, R. P. \& Manns, J. G. (1974). Effects of glucagon on activities of hepatic enzymes in sheep. Cornell Veterinarian 64, 217-224.

Brockman, R. P. \& Manns, J. G. (1985). Characterization of antiserum 26GP for radioimmunoassay of glucagon in sheep plasma. Canadian Journal of Animal Science 65, 765-768.

Canadian Council on Animal Care (1984). Guide to the Care and Use of Experimental Animals, 2 vols. Ottawa, Ontario: CCAC.

DeBodo, R. C., Steele, R., Altszuler, N. A., Dunn, A. \& Bishop, J. S. (1964). On hormonal regulation of carbohydrate metabolism: studies with ${ }^{14} \mathrm{C}$-glucose. Recent Progress in Hormone Research 19, $445-482$.

Filsell, O. H., Jarrett, I. G., Taylor, P. H. \& Keech, D. B. (1969). Effects of fasting, diabetes and glucocorticoids on gluconeogenic enzymes in the sheep. Biochimica Biophysica Acta 184, 54-63.

Judson, J. G. \& Leng, R. A. (1973). Studies on the control of gluconeogenesis in sheep: effect of propionate, casein and butyrate infusions. British Journal of Nutrition 29, 175-195.

Katz, M. L. \& Bergman, E. N. (1969a). A method of simultaneous cannulation of the major splanchnic blood vessels of the sheep. American Journal of Veterinary Research 30, 655-661.

Katz, M. L. \& Bergman, E. N. (1969 b). Hepatic and portal metabolism of glucose, free fatty acids and ketone bodies in the sheep. American Journal of Physiology 216, 953-960.

Leng, R. A. (1970). Glucose synthesis in ruminants. Advances in Veterinary Science 14, 209-260.

Leng, R. A. \& Annison, E. F. (1963). Metabolism of acetate, propionate and butyrate by sheep-liver slices. Biochemical Journal 86, 319-327.

Li, J. C. R. (1964). Statistical Inference, vol. 1. Ann Arbor, MI: Edwards Brothers Inc.

Lomax, M. A. \& Baird, G. D. (1983). Blood flow and nutrient exchange across the liver and gut of the dairy cow. British Journal of Nutrition 49, 481.496.

Ravussin, E. \& Bogardus, C. (1982). Thermogenic response to insulin and glucose in man: a model to evaluate the different components of the thermic effect of carbohydrate. Life Sciences 31, 2011-2018.

Soling, H. D. \& Seuffert, C. D. (1975). Direct in vitro effects of insulin on liver metabolism. In Handbook of Physiology of Insulin, part 2, pp. 413-433. [A. Hasselblatt and F. v. Bruchhausen, editors]. New York: SpringerVerlag.

White, A. L., Handler, P., Hill, R. L. \& Lekman, I. R. (1978). Lipid Metabolism I. In Principles of Biochemistry, 6th ed, pp. 568-606. New York: McGraw-Hill. 